\title{
JORNALISMO INSTITUCIONAL NO TWITTER: PARTICIPAÇÃO E INCLUSÃO DO LEITOR COMO ESTRATÉGIA DE LEGITIMAÇÃO DO JORNAL ZERO HORA ${ }^{1}$
}

\author{
INSTITUTIONAL JOURNALISM ON TWITTER: READER'S PARTICIPATION \\ AND INCLUSION AS LEGITIMATION STRATEGY OF THE ZERO HORA \\ NEWSPAPER
}

\author{
PERIODISMO INSTITUCIONAL EN TWITTER: LA PARTICIPACIÓN Y LA \\ INCLUSIÓN DEL LECTOR COMO UNA ESTRATEGIA DE LEGITIMACIÓN \\ DEL PERIÓDICO ZERO HORA
}

Luciana Menezes Carvalho

Doutoranda, Universidade Federal de Santa Maria lucianamenezescarvalho@gmail.com

Eugenia Maria Mariano da Rocha Barichello Doutora, Universidade Federal de Santa Maria eugeniamarianodarocha@gmail.com

\section{Resumo}

Neste trabalho, parte-se do pressuposto de que as mídias sociais digitais desencadeiam processos de desintermediação e deslegitimação do campo institucional do jornalismo, e que as organizações que dele fazem parte adotam estratégias para legitimar seu papel social de mediação no uso dessas mídias. Para investigar a questão, desenvolveu-se análise de conteúdo de duas coberturas jornalísticas no perfil do jornal Zero Hora no Twitter, em que foram identificadas quatro categorias principais de uso da ferramenta. Elas indicam estratégias para envolver o leitor e incentivar sua participação nas coberturas.

Palavras-chave: Estratégias de legitimação. Instituição jornalística. Mídias sociais digitais.

\begin{abstract}
This work starts from the assumption that digital social media trigger processes of disintermediation and institutional delegitimation of the institutional field of journalism, and the organizations that take part of it use strategies to legitimize their social role of mediation in the use of these media. In order to investigate the issue, we developed a content analysis in two news coverages in the newspaper Zero Hora's profile on Twitter, in which four main categories of use of the tool were identified. They suggest strategies to engage the reader and encourage him participation in coverage.
\end{abstract}

Keywords: Legitimation strategies. Journalistic institution. Digital social media.

Esta obra está licenciada sob uma Licença Creative Commons

\footnotetext{
${ }^{1} \mathrm{O}$ artigo traz um recorte de pesquisa desenvolvida na dissertação de Mestrado de nossa autoria e orientação, respectivamente.
} 


\section{Resumen}

En este trabajo se parte del supuesto de que los medios sociales digitales generan procesos de desintermediación y deslegitimación del campo institucional del periodismo, y que las organizaciones que lo integran se valen de estrategias para legitimar su papel social de mediación en el uso de dichos medios. Para investigar la cuestión, se desarrolló un análisis de contenido de dos coberturas periodísticas en el perfil del periódico Zero Hora en el Twitter, en que se identificaron cuatro categorías principales en el uso de la herramienta. Ellos sugieren estrategias para involucrar al lector y fomentar su participación en la cobertura.

Palabras clave: Estrategias de legitimación. Institución periodística. Medios sociales digitales.

\section{INTRODUÇÃO}

O jornalismo é uma instituição social cujo papel central é a mediação informativa, legitimada em sua matriz hegemônica através do discurso da objetividade (Guerra, 2008), por meio de uma lógica de comunicação baseada no modelo massivo de transmissão e difusão de informações. Tal lógica vê-se em crise diante da atual ambiência midiatizada, caracterizada por possibilidades de interação mútua e mediação descentralizada, envolvendo participação, conversação e uma lógica de fluxos em rede (SAAD, 2008).

A questão central neste trabalho foi investigar as possíveis estratégias, visando à legitimação, adotadas pelo campo institucional do jornalismo por meio de suas organizações, diante das práticas desintermediadoras das mídias sociais digitais. Delimitamos a pesquisa aos usos dados pelo jornal Zero Hora ao serviço de micromensagens Twitter $^{2}$, onde investigamos as estratégias de legitimação emergentes no conteúdo das postagens referentes à cobertura de dois acontecimentos, com um intervalo de cerca de um ano entre um e outro.

O artigo está dividido em três partes. Na primeira, discutimos brevemente a noção de mídia social digital e suas relações com o jornalismo; na segunda, fazemos um relato da análise de conteúdo aplicada nos posts do perfil @zerohora; na terceira e última, discutimos os resultados, em que os usos dados pelo jornal no Twitter são relacionados à reflexão sobre as estratégias de legitimação institucional da organização analisada ${ }^{3}$.

\footnotetext{
${ }^{2}$ Serviço de micromensagens ou microblogging fundado em 2006 nos Estados Unidos. Disponível no endereço: http://twitter.com

${ }^{3}$ A teorização sobre legitimação não é aprofundada neste trabalho devido à opção por uma ênfase nos resultados da investigação empírica, sendo discutida apenas na parte da interpretação dos resultados, de modo analítico.
} 


\section{MÍDIAS SOCIAIS DIGITAIS E JORNALISMO}

A denominação mídia social ganhou força a partir de algumas apropriações das possibilidades da web 2.0 - termo cunhado por Tim O’Reilly (2005) - para explicar um conjunto de transformações da web, com destaque ao papel ativo do usuário (SAAD, 2008). Ela é caracterizada como uma plataforma na qual o conteúdo é gerado pelos interagentes e não apenas por editores e programadores, como ocorria na fase anterior, com sites mais estáticos que ofereciam pouca possibilidade de interação. Na atual fase, a web ultrapassa a conexão entre computadores, passando a conectar pessoas, o que se dá, cada vez mais, por meio de dispositivos móveis.

A ideia de que toda mídia deveria, por essência, ser social, cria a necessidade de uma maior delimitação ao termo, optando-se por mídia social digital para caracterizar esta nova ambiência de fluxos informacionais e comunicacionais. As mídias sociais digitais são sistemas que possibilitam usos e apropriações que envolvem participação ativa do interagente através de comentários, recomendações, disseminação e compartilhamento de conteúdo próprio ou de terceiros.

Esses meios carregam em si uma potencialidade para o uso social. São exemplos de ferramentas de mídia social digital, serviços como Twitter ${ }^{4}$, Facebook ${ }^{5}$, Youtube ${ }^{6}$, Flickr ${ }^{7}$, Slideshare $^{8}$, Instagram ${ }^{9}$, cada um atuando de modo distinto e possibilitando usos combinados, conforme as apropriações dos atores.

Segundo Saad (2008, p. 150), as principais características desse ambiente de mídia social são: a ruptura do predomínio do pólo de emissão; a criação de canais independentes de informação e conversação; alto grau de envolvimento e personalização pelos usuários; alto grau de articulação coletiva; concentração em um mesmo ambiente de ferramentas de produção de conteúdo e participação e diálogo.

\footnotetext{
${ }^{4}$ Idem nota 2.

${ }^{5}$ Serviço de rede social criado em 2004, nos Estados Unidos. Permite a criação de perfis pessoais e 'fanpages' (páginas para uso institucional ou comercial). Disponível em: <http://www.facebook.com>.

${ }^{6}$ Serviço de compartilhamento de vídeos fundado em 2005. Disponível em: <http://www.youtube.com>

${ }^{7}$ Serviço de hospedagem e compartilhamento de imagens fundado em 2004, no Canadá. O serviço permite que as imagens sejam etiquetadas através de 'tags', funcionando também como um fotolog. Disponível em: $<$ http://www.flickr.com/>.

${ }^{8}$ Outro serviço considerado típico da web 2.0. É focado no carregamento e compartilhamento de apresentações e arquivos de texto. Disponível em: <http://slideshare.net>.

${ }_{9}$ Aplicativo que possibilita ao usuário tratar suas fotos instantaneamente através do celular e compartilhá-las nos serviços de rede social. Foi inicialmente projetado para uso exclusivo em dispositivos móveis da Apple. Atualmente, está disponível também no sistema Android, suportado por uma maior variedade de aparelhos. Disponível em: <http://instagr.am/>.
} 
A denominada ruptura do predomínio do pólo de emissão está relacionada à possibilidade de que os antigos receptores da mídia de massa agora atuem também como emissores na mídia social digital; o poder de informar deixa de ser exclusividade de uma instituição. Ao mesmo tempo, esses interagentes distribuem informações e conversam através dos canais independentes das mídias sociais digitais e dos sites de rede social.

Ainda que sejam utilizadas tanto por usuários independentes quanto por atores sociais corporativos, de forma estratégica - podendo ser apropriadas de modo massivo - as ferramentas de mídia social digital, diferentemente do que ocorre com os meios de comunicação de massa tradicionais, como o jornal impresso, a TV e o rádio, circulam em outra lógica, não linear, em rede e interativa, em que os usuários não precisam de autorização da esfera produtiva para se manifestar.

Essa lógica não linear da comunicação na ambiência digital é apropriada pelas organizações jornalísticas em seus espaços institucionais, como é o caso do perfil de Zero Hora no Twitter. O serviço é uma das principais manifestações dessa nova ambiência midiática, em que a apropriação dos interagentes determina sua função social.

Para a organização jornalística, as ferramentas de mídias social são utilizadas visando promover maior interação entre o jornal e o público, aproximar o jornalista de seu leitor, facilitar a pauta e a apuração e manter ou captar novos leitores por meio de estratégias que incluem busca por visibilidade, legitimação, promoção, divulgação de notícias.

Para os interagentes pode representar uma nova forma de se manter informado a partir das postagens de uma organização jornalística no próprio espaço da mídia social; o caráter institucional de toda a construção da notícia nesses espaço confere à informação recursos como credibilidade e legitimidade, mesmo em um espaço regido por uma lógica conversacional. Especialmente no Twitter, a apropriação informativa voltada para fins jornalísticos recebe parte significativa da atenção dos usuários.

Neste trabalho, a hipótese era a de que as organizações informativas lançam mão de estratégias nas mídias sociais digitais para se legitimar nesses espaços marcados pela conversação e o relacionamento entre os atores. Por meio da interpelação aos interagentes, inclusão do leitor nas coberturas, compartilhamento de conteúdo de terceiros e conversação com os seguidores no Twitter, desenvolve-se um novo processo de legitimação institucional não mais baseado apenas no papel tradicional de transmissão de informações do jornalismo. 


\section{Coberturas jornalísticas no twitter de @Zerohora}

A pesquisa foi guiada pela metodologia de Análise de Conteúdo (AC) em sua vertente qualitativa (BARDIN, 1977) voltada para o jornalismo, conforme proposto por Herscowitz (2007). A AC foi aplicada em duas etapas, cada uma referente a uma cobertura jornalística do jornal Zero Hora em seu perfil no Twitter. A primeira refere-se às postagens sobre um temporal e ficou delimitada entre 18/11/2009 e 18/12/2009. A segunda foi desenvolvida entre 05/12/2010 e 05/01/2011 e tinha como foco postagens sobre trânsito.

Levamos em conta as características do Twitter e as principais apropriações apontadas pela literatura para a categorização das unidades de análise. Java et al (2007) apontaram em uma amostra obtida da timeline da ferramenta os seguintes usos com relação à intenção dos autores dos tweets: falas diárias; conversação; compartilhamento de informação; e notícias. Reformulamos as categorias em função de nossa análise ser focada nas postagens de uma organização jornalística, e não em uma amostra aleatória conforme o trabalho dos autores. Assim, operamos uma adaptação dessas categorias de análise, que emergiram de uma observação exploratória no corpus de pesquisa, apontando os usos predominantes no primeiro conjunto de posts. Na Tabela 1, estão elencadas as categorias de análise e os critérios correspondentes que foram utilizados para a categorização. 
Tabela 1 - Categorias e seus critérios

\begin{tabular}{|l|l|}
\hline CATEGORIA & CRITÉRIO \\
\hline $\begin{array}{l}\text { Difusão } \\
\text { informações }\end{array}$ & $\begin{array}{l}\text { Unidades de análise em que predomina a tradicional função } \\
\text { informativa do jornalismo, indicando a intenção do autor do post de } \\
\text { divulgar manchetes, notícias da própria Zero Hora. }\end{array}$ \\
\hline Participação & $\begin{array}{l}\text { Tweets em que o perfil do jornal busca interpelar os seus seguidores } \\
\text { para que enviem relatos, fotos ou vídeos sobre o acontecimento, } \\
\text { principalmente por meio do uso de verbos como “envie”, "mande”, } \\
\text { "colabore”, “participe”. O principal critério para enquadramento de } \\
\text { um tweet nessa categoria foi o predomínio da intencionalidade de } \\
\text { convite à participação. }\end{array}$ \\
\hline Compartilhamento & $\begin{array}{l}\text { Tweets que indicam a intenção de replicar à rede de followers uma } \\
\text { mensagem recebida de outrem (por meio do retweet, ou RT). }\end{array}$ \\
\hline Conversação & $\begin{array}{l}\text { Posts que indicam menção a outro perfil do Twitter, seja leitor, fonte } \\
\text { ou jornalista, manifestando a intenção de interagir. A pesquisa de Java } \\
\text { et al (2007) apontou a presença do sinal de @ na frente do nome de } \\
\text { usuário como marca de conversação, no entanto não levaram em } \\
\text { conta que o @ também aparece quando se replica uma mensagem } \\
\text { (por meio do RT, que é o retweet), conforme alertam Consoni e } \\
\text { Oikawa (2009, p. 7) em análise sobre os usos predominantes do } \\
\text { Twitter. Portanto, para se detectar a conversação, realizamos uma } \\
\text { análise contextual do tweet para além da mera presença do @ antes do } \\
\text { nome de usuário, levando em conta a intencionalidade. }\end{array}$ \\
\hline
\end{tabular}

Fonte: elaborado pelas autoras

A partir das categorias estabelecidas, foi feita a classificação dos tweets nesta primeira etapa da análise, relativa à cobertura do temporal desenvolvida no perfil do Twitter de Zero Hora. As mesmas categorias foram posteriormente mantidas para a análise da segunda cobertura a fim de se atingir um dos objetivos da AC, que é a homogeneidade na categorização.

\subsection{Cobertura do \#temporalrs}

Na seleção dos tweets analisados nesta primeira etapa, utilizamos um critério semântico, com base na presença de palavras e termos relacionados ao tema "temporal no Rio Grande do Sul” (chuvas, ventos fortes, temporal, “temporalpoa”, “temporalrs”), ao contexto das mensagens (estragos causados pela chuva, falta de energia elétrica, problemas na infraestrutura urbana etc) e à questão da participação dos leitores na cobertura do temporal (com a presença de termos como “envie alertas”, “mande fotos”, “colabore”, “participe”).

Assim, o corpus de análise ficou constituído de 81 tweets, correspondendo a $41 \%$ de todos os posts do período. Dividimos os 81 tweets que compõem este primeiro corpus conforme as categorias de análise expostas na Tabela 1. 
Nesta primeira etapa, a categorização adotada revelou um uso predominante do Twitter por ZH para fins informativos, com 65\% do total de tweets relacionados à categoria difusão de informações.

Com 12 unidades (15\% do total do corpus), em segundo lugar como uso mais corrente no caso analisado, apareceu a categoria participação, reunindo os tweets destinados a solicitar a colaboração dos leitores na cobertura do acontecimento e sua participação em espaços interativos do jornal.

Os outros usos mais frequentes no acontecimento \#temporalrs foram o compartilhamento de informações recebidas de outros perfis (através do retweet, com 9,9\% das unidades) e a conversação (9,9\%), reunindo os tweets que mencionavam perfis específicos, incluindo respostas ou agradecimentos por parte do jornal aos seguidores.

\subsection{Cobertura do \#transito}

O ponto de partida para a constituição do segundo corpus foi o início do veraneio, quando muitos gaúchos dirigem-se ao litoral, intensificando o tráfego nas estradas. Selecionamos um mês de postagens que pudesse congregar a cobertura sobre o tema escolhido. Assim, iniciamos a seleção dos tweets no dia 05/12/2010, encerrando no dia 05/01/2011. Neste período, Zero Hora postou em seu perfil um total de 849 mensagens (ou tweets). Deste total, selecionamos aqueles que se relacionavam à cobertura sobre trânsito no Estado, passando a constituir nosso corpus de análise, nesta segunda etapa da AC, um conjunto de 141 tweets.

Nesta cobertura, a categoria com maior número de tweets foi a de compartilhamento, em que se enquadram os retweets (RTs) dados por @zerohora, conforme critério estabelecido previamente e aplicado às duas etapas de análise. Um total de 92 tweets correspondeu a esta categoria, ou seja, 65,7\% do corpus sobre trânsito no período de um mês. Uma primeira diferença em relação à primeira cobertura, em que a categoria predominante foi a de difusão de informações e a de compartilhamento apareceu em terceiro lugar.

A categoria compartilhamento apresentou, ainda, outra distinção em relação à primeira etapa da AC. Enquanto no corpus sobre o temporal (corpus 1), os retweets dados pelo perfil de @zerohora diziam respeito em sua maioria à replicação de informações dadas por perfis de jornalistas do próprio jornal ou do grupo RBS, ou ainda de organizações e assessorias (como da companhia de energia elétrica, a CEEE), no corpus sobre trânsito a categoria reuniu um 
grande número de RTs pelos quais o jornal replica informações dos leitores (seguidores de @zerohora), dado que não apareceu na primeira etapa da AC.

Até mesmo em função de não ter emergido tal situação é que na categoria participação incluímos, na primeira etapa, os posts em que @zerohora solicita a participação dos leitores, e não a própria participação deles, que ficou diluída ou não representou um dado significativo naquele momento. Somente na segunda etapa da AC, é que essa participação apareceu na categoria compartilhamento, enquanto que a solicitação de colaboração feita pelo jornal diminuiu.

Em segundo lugar em número de tweets, destacou-se a categoria difusão de informações, com 32 unidades correspondentes a 26,4\% do total. Na primeira cobertura, ela apareceu em primeiro lugar, com 65\% do total.

Em terceiro lugar, apareceu a categoria participação, com seis tweets, ou 4,2\% do total deste corpus. Em relação ao primeiro, houve uma queda nesse tipo de uso do Twitter por parte de Zero Hora.

Como já mencionamos na análise da categoria compartilhamento, percebemos um deslocamento da participação e uma mudança de sentido desta categoria em relação ao primeiro corpus. Como a maior parte de tweets envolvendo a ideia de participação na primeira etapa dizia respeito à solicitação de colaboração dos seguidores por parte do perfil de Zero Hora, o critério para essa categoria foi a presença desse tipo de interpelação ao leitor.

Como a segunda etapa deveria contemplar os mesmos critérios, para que a comparação fosse possível, mantivemos a categoria participação reunindo os posts desse tipo. No entanto, a ideia de participação que se sobressaiu não contemplou esse mesmo critério, pois um número reduzido de tweets tinha como conteúdo a interpelação aos seguidores. A ideia de participação, neste caso, deslocou-se para a divulgação, por parte de @zerohora, das colaborações enviadas pelos seguidores, que foram retweetadas e, portanto, entraram na categoria compartilhamento.

Por último, em quarta posição ficou a categoria conversação, com cinco tweets correspondendo a 3,5\% do total do corpus 2 .

\section{Estratégias emergentes de legitimação}

Embora a ideia de estratégia esteja relacionada à de planejamento, nem sempre as estratégias são deliberadas, planejadas pela alta diretoria de uma organização. Muitas vezes, os valores da empresa, sua cultura organizacional e o perfil de seus colaboradores fazem com 
que processos estratégicos ocorram de modo menos programado, por decisão de departamentos ou mesmo por iniciativas individuais que, pelos resultados, aprecem ligadas a um projeto maior da organização, aos seus valores e missão.

Nesse caso, temos as estratégias emergentes, que se desenvolvem sem intenções ou apesar delas. As estratégias emergentes estão relacionadas com um padrão de comportamento e ação que pode surgir e ser reconhecido, identificado (MINTZBERG, 2006, p. 27). Elas se opõem às estratégias deliberadas, que são resultado de uma pretensão prévia da organização com sua implementação pensada em todos os passos a priori. Para Mintzberg (2006), a maioria das estratégias envolve os dois tipos ao mesmo tempo, refletindo aspectos deliberados e emergentes.

Entendemos que a noção de estratégia emergente é adequada ao nosso objeto de estudo, caracterizado pelo seu tom de novidade para as organizações e para o público, embora as mídias sociais digitais estejam cada vez mais presentes nas empresas jornalísticas e nos produtos que elas desenvolvem. Sendo um tema que ainda está sendo mapeado pelo meio acadêmico, e analisado pelo mercado jornalístico, pensar em estratégias para a mídia social digital é lidar com possibilidades, nunca com certezas.

Conforme resultados da primeira etapa da análise de conteúdo, com a categoria difusão de informações predominando nos usos do Twitter pelo jornal Zero Hora, o papel social que legitima o jornalismo - desde sua institucionalização a partir da hegemonia que adquiriu a matriz informativa (GUERRA, 2008) - é reforçado nessa ferramenta de mídia social por meio da distribuição de notícias, seguindo a lógica de transmissão que caracteriza a mídia de massa.

A organização, enquanto representante da instituição jornalismo informativo, atualiza seu papel de mediação a partir desse uso do Twitter como mais um suporte midiático, sem que haja alguma ruptura em relação à lógica de transmissão pela qual o jornalismo tem se legitimado em sua matriz informativa. É um uso que caracteriza muito mais uma continuidade, nesse aspecto, do que uma ruptura em relação aos outros meios (PALACIOS, 2002).

A organização, ao priorizar a difusão de informações no Twitter, aproveita o crescimento do serviço como mídia informativa, dando aos seus seguidores (followers) aquilo que tem aparecido como mais importante entre os usos gerais da ferramenta, que é a troca de informações, sobretudo de interesse jornalístico (KWAK et al, 2010). A circulação de informações, sobretudo as de caráter jornalístico, tem sido apontada como um fator importante nas apropriações da ferramenta, influenciando as trocas entre os atores na rede 
social (RECUERO, 2009; ZAGO, 2009; RECUERO e ZAGO, 2010, 2012). Conforme os trabalhos desenvolvidos pelas autoras sobre o que motiva os atores a compartilhar informações no Twitter, fica evidente que a credibilidade das informações jornalísticas auxilia na construção da reputação nas redes sociais. Com o fluxo de informações produzidas e disseminadas pelos próprios interagentes crescendo, as organizações jornalísticas passam a marcar presença nesses espaços em busca de legitimação de seu papel social de intermediação.

Ao promover seu principal papel social na ferramenta, difundindo informações, Zero Hora reafirma sua importância como intermediário, assumindo a responsabilidade pela apuração, seleção, atestando a credibilidade das informações. Seria uma nova direção ao papel de intermediação do jornalismo, na medida em que o jornal assumiria nas mídias sociais digitais uma função de filtro, de mediador do público no sentido de contextualizar, apurar, personalizar as informações, e não simplesmente distribuí-las.

Esse uso informativo do Twitter, no entanto, não obedece a uma lógica transmissionista da comunicação de massa. Ou seja, é intermediação informativa, mas atualizada, renovada pelas peculiaridades da mídia social digital. Surgem outras possibilidades de informar, como é o caso das informações de bastidores que aparecem em alguns tweets, ampliando as informações que as pessoas podem ter do acontecimento, em um processo de abertura típico da midiatização.

A categoria participação, que ficou em segundo lugar em número de tweets na primeira cobertura analisada, mostra uma potencialização, no Twitter de Zero Hora, das possibilidades interativas da mídia digital no atual estágio da web 2.0, com o fortalecimento de seu aspecto social; ou ainda uma ruptura se pensarmos na possibilidade de inclusão do leitor no processo de produção da notícia que ocorre nas mídias sociais digitais na comparação com o modelo da mídia de massa, em que o leitor estava limitado ao consumo das informações. Com o uso das possibilidades participativas do Twitter, na cobertura de um acontecimento, ZH empodera o leitor, ainda que com limites, no processo de produção da notícia.

Com relação à categoria conversação, que apresentou uma pequena amostra de tweets na primeira cobertura analisada, acreditamos que ela tenha emergido muito mais por questões circunstanciais do que estratégicas. Ainda assim, a conversação reflete uma transformação nos modos pelos quais o jornalismo vem se legitimando, subvertendo a lógica transmissiva da mídia de massa. 
Quanto à categoria compartilhamento de conteúdo que emergiu na categorização realizada no primeiro corpus de análise, a partir da apropriação pelo perfil de @zerohora da funcionalidade retweet do Twitter, consideramos uma possível ruptura em relação à lógica massiva, conforme considerada por Palácios (2002). Isto porque, embora possa parecer uma apropriação trivial de uma funcionalidade do serviço de micromensagens, o compartilhamento de informações indica certa inversão de papeis no jornalismo informativo. O leitor está sendo usado como fonte de legitimidade, garantindo credibilidade à cobertura do jornal.

O efeito de verdade que pauta o jornalismo em sua matriz informativa por meio das mídias de massa, no Twitter poderia estar sendo buscado de modo mais complexo, através de efeitos de participação. Seria esse um sinal de transformação no processo de legitimação institucional da organização jornalística a partir das práticas desintermediadoras (LEVY, 1998) e deslegitimadoras (LYOTARD, 2000) que ocorrem nos fluxos das mídias sociais digitais.

A segunda etapa da análise de conteúdo fez emergir novas questões sobre o uso informativo que Zero Hora faz do seu perfil no Twitter e sobre as estratégias de legitimação institucional que mobiliza nessa prática. As categorias que utilizamos para classificar os tweets desse segundo corpus não emergiram dos usos que encontramos, ao contrário do que ocorreu na primeira etapa da AC. Isso porque o objetivo, neste segundo momento, era testar a metodologia já aplicada na primeira etapa e confirmar resultados, ou refutá-los. O que emergiram foram novos resultados, apesar de ter sido possível encontrar as mesmas categorias nos principais usos do Twitter por Zero Hora, conforme já descrevemos.

Uma das primeiras mudanças que percebemos de uma cobertura para outra foi o número de posts totais, indicando um aumento na frequência com que @zerohora é atualizado. Enquanto o corpus 1 foi constituído de 81 tweets sobre o temporal no período de um mês, o corpus 2 incluiu 141 tweets sobre trânsito em um mesmo período de tempo, um crescimento de 74\%. Não emergem maiores interpretações aqui, pois são assuntos diferentes que envolvem outras questões, portanto não seria possível inferir que se trata de uma mudança na utilização da ferramenta, servindo esses dados apenas como ilustração.

As mudanças que nos interessam a título de análise estão ligadas à categorização. Como podemos observar nos resultados da análise da segunda cobertura, houve uma significativa mudança, em comparação à primeira no uso predominante do Twitter. Enquanto na primeira, o uso mais comum foi correspondente à categoria difusão de informações, indicando certa manutenção da mediação centralizada por parte do jornal na ambiência da mídia social digital, um ano após, na cobertura de trânsito, a preferência do jornal foi pelo 
compartilhamento de informações e, sobretudo, de informações geradas pelos seguidores. Ou seja, há uma indicação de que a organização, enquanto representante da instituição jornalismo informativo, começa a se apropriar de modo cada mais intenso das potencialidades interacionais da mídia social digital, chegando a sobrepor a participação do leitor à mera difusão de informações.

Muitos dos posts de trânsito dizem respeito a hashtag “\#naestrada”, identificando uma cobertura colaborativa proposta por @zerohora. Assim, muitos dos RTs são postagens dos leitores, com textos e imagens, atendendo ao pedido do jornal para atuarem como repórteres na cobertura da movimentação do trânsito nas rodovias gaúchas durante o feriadão de Natal e Ano-Novo. As informações eram postadas em tempo real, indicando o uso do Twitter como plataforma jornalística colaborativa.

O compartilhamento de informações por si só representa uma possibilidade da mídia social digital que opera uma ruptura em relação à lógica de transmissão da mídia de massa, no sentido pensado por Palácios (2002). Quando colocado em primeiro lugar como uso do Twitter, o compartilhamento pode revelar que Zero Hora começa a valorizar as potencialidades oferecidas pela mídia social digital para além do papel de mediação do jornalismo, tão presente no processo de legitimação institucional no modelo de comunicação de massa. Nessa perspectiva, acreditamos que, a partir da análise da segunda cobertura, fez mais sentido pensar em uma crise de legitimação institucional do jornalismo, com deslocamentos, na ambiência da mídia social digital, no papel central pelo qual ele sempre se legitimou.

Ainda assim, a organização está reforçando, possivelmente, seu papel de intermediária. Trata-se, agora de modo mais intenso, de uma renovação nesse papel que legitima o jornalismo institucionalmente, com a inclusão do leitor (seguidor de @zerohora) em sua prática de informar. Inclusão do leitor que se dá de modo estratégico, conforme pensado por Saad (2008) e Boyd (2010), para garantir um discurso mais plural e em acordo com a lógica das mídias sociais digitais.

A importância que continua tendo, nessa ambiência de participação, o papel de mediação informativa do jornalismo, é confirmada pela presença da categoria difusão de informações como o segundo uso mais frequente do Twitter na segunda cobertura analisada. Ou seja, se também informa quando compartilha as informações enviadas pelos seguidores, mesmo que diminua as postagens em que difunde notícias do próprio jornal, Zero Hora continua exercendo seu papel de mediação informativa já desempenhado nas outras plataformas (impresso, site etc), promovendo, no entanto, atualizações no modo de informar, 
tornando-o mais participativo, conversacional, por contar com o leitor como um colaborador e fazer questão de tornar isso público (por meio do RT).

A questão da participação, nesta segunda etapa da AC, vai além da interpelação de Zero Hora aos seguidores de seu perfil (como emergiu na primeira etapa), aparecendo, como já demonstrou nossa interpretação, no conteúdo dos tweets que entraram na categoria compartilhamento. Assim, não poderíamos inferir que a importância da participação diminuiu, pois estaríamos ignorando o que o conteúdo manifesta após uma análise mais global e aprofundada do corpus.

Diminuiu, sim, o número de tweets que integram a categoria participação, que assim foram enquadrados por utilizarmos os mesmos critérios usados na categorização da primeira cobertura; mas não diminuiu a ideia de participação no uso do Twitter por Zero Hora, como mostrou nossa análise dos posts que integram a categoria compartilhamento, a maioria formada por retweets para colaborações enviadas pelos leitores - ou seja, a ideia da participação cresceu com a inclusão do leitor na difusão de informações.

A conversação, mais uma vez, manteve-se limitada a um número pequeno de posts, inclusive tendo diminuído. Acreditamos que não houve uma mudança nesse aspecto e que ele continua sendo pouco estratégico para Zero Hora, que parece conversar diretamente com os seguidores apenas em casos pontuais, sem uma preocupação em passar uma imagem de que está aberta ao diálogo no Twitter. Parece que a variação na porcentagem de tweets que integram essa categoria não interfere no resultado global da prática informativa de Zero Hora no Twitter.

A conversação, enquanto diálogo, no Twitter, ainda é pouco utilizada por @zerohora, sendo uma potencialidade talvez ainda em aberto, entendida como um meio para resolução de dúvidas e encaminhamento de reclamações que acabam sendo tratadas, atualmente, muito mais por meio de mensagens diretas (DMs, ou Messages) que não ficam disponíveis a todos os seguidores, do que de modo aberto.

\section{CONSIDERAÇÕES}

A análise de conteúdo revelou algumas diferenças nas estratégias de uso do Twitter pelo jornal Zero Hora entre uma e a outra cobertura analisada. Em relação às estratégias de legitimação emergentes, destacou-se a questão da importância dada pela organização jornalística a dois usos da ferramenta - o compartilhamento de informações e a participação do leitor na cobertura de um acontecimento. 
A inclusão do leitor (seguidor) na cobertura, sendo retweetado pelo perfil de Zero Hora, revela, em nossa avaliação, uma estratégia emergente de legitimação por meio do discurso da participação; discurso este que já estava presente nos primeiros usos do Twitter pela organização, mas que se reforça em um segundo momento.

Entendemos que houve uma atualização importante do papel de mediação informativa, que deixou de ser tão centralizado pelo jornal, passando a dar mais espaço à colaboração dos leitores que seguem o perfil @zerohora no Twitter. A mudança que percebemos entre o primeiro e o segundo corpus mostra um possível crescimento, no período, da utilização estratégica do Twitter pela organização a partir do reforço da inclusão do leitor na cobertura do jornal.

Se a AC nos permitisse generalizações, poderíamos vislumbrar, na evolução dos usos do Twitter por parte de Zero Hora, tendências de uso das mídias sociais pelo campo institucional do jornalismo, voltadas para um novo papel de mediação. Tais possibilidades poderão ser testadas em novos estudos, tendo como objeto outras organizações e ferramentas digitais.

\section{REFERÊNCIAS}

BARDIN, Laurence. Análise de conteúdo. Tradução Luís A. Reto e Augusto Pinheiro. França, Edições 70, 1977.

BOYD, D. Streams of Content, Limited Attention: the flow of information through social media. Educause Review, vol. 45, no. 5 - September-october 2010, p. 26-36. Disponível em:

<http://www.educause.edu/EDUCAUSE+Review/EDUCAUSEReviewMagazineVolume45/S treamsofContentLimitedAttenti/213923>. Acesso em 10/11/2010.

HERSCOVITZ, Heloiza Golbspan. Análise de conteúdo em jornalismo. In: LAGO, C. BENETTI, M. Metodologia de Pesquisa em Jornalismo. Petrópolis: Vozes, 2007.

GUERRA, J. L. O percurso interpretativo na produção da notícia: verdade e relevância como parâmetros de qualidade jornalística. São Cristóvão: Editora UFS; Aracaju: Fundação Oviêdo Teixeira, 2008.

JAVA, A., SONG, X., FININ, T., \& TSENG, B. Why We Twitter: Understanding Microblogging Usage and Communities. 9th WEBKDD and 1st SNA-KDD Workshop '07. San Jose, California, USA, 2007. Disponível em <http://ebiquity.umbc.edu/get/a/publication/369.pdf>. Acesso em 05/06/2009. 
KWAK, H. et al. What is Twitter, a social network or a news media? WWW'10 Proceedings of the 19th internacional conference on World Wide Web. Raleigh, USA, 2010. Disponível em: http://an.kaist.ac.kr/traces/WWW2010.html. Acesso em 20/12/2010.

LEVY, P. A Revolução contemporânea em matéria de comunicação. Tradução Juremir Machado da Silva. Revista FAMECOS, Porto Alegre, nº 9, dezembro 1998.

LYOTARD, J. F. A condição pós-moderna. Rio de Janeiro: José Olympio, 2000. 6a ed., 131 p.

MINTZBERG, H. Cinco Ps para Estratégia. In: MINTZBERG, H. et al. O processo da estratégia: conceitos, contextos e casos selecionados. São Paulo: Bookman, 2006.

O’REILLY, Tim. Web 2.0: compact definition. Message posted to http://radar. oreilly. com/archives/2005/10/web_20_compact_definition. html (2005).

PALACIOS, M. Jornalismo Online, Informação e Memória: apontamentos para debate (2002). Disponível em:

<http://www.facom.ufba.br/jol/pdf/2002_palacios_informacaomemoria.pdf>

Acesso em 15/10/2010.

RECUERO, Raquel. Redes sociais na Internet, difusão de informação e jornalismo: elementos para discussão. Metamorfoses jornalísticas. Santa Cruz do Sul: EDUNISC, 2009.

RECUERO, Raquel. ZAGO, Gabriela. RT, por favor: considerações sobre a difusão de informações no Twitter. In: Fronteiras-estudos midiáticos 12.2, 2010, p. 69-81.

Informações e Capital Social no Twitter. Revista Contracampo, no. 24, 2012, p. 19-43

SAAD, Beth. Estratégias 2.0 para a mídia digital: internet, informação e comunicação. São Paulo: Editora Senac São Paulo, 2008.

ZAGO, Gabriela da Silva. O Twitter como suporte para produção e difusão de conteúdos jornalísticos. Ciberlegenda, No 21, 2009. 
Original recebido em: 30/04/2013

Aceito para a publicação em: 20/07/2013

Luciana Menezes Carvalho

Doutoranda no Programa de pós-Graduação em Comunicação da UFSM. Professora no Centro Universitário Franciscano (Unifra)

Eugenia Maria Mariano da Rocha Barichello

Doutora em Comunicação (UFRJ), professora associada e coordenadora do Programa de Pós-Graduação em Comunicação da UFSM. 